\title{
GENOTYPING OF MYCOBACTERIUM TUBERCULOSIS IN NEW SOUTH WALES: RESULTS FROM 18 MONTHS OF A STATEWIDE TRIAL
}

Peter Jelfs, Vitali Sintchenko and Gwendolyn L Gilbert Centre for Infectious Diseases and Microbiology

- Public Health

Sydney West Area Health Services, Westmead

Several molecular typing methods are available to assist public health practitioners in identifying clusters of recently acquired tuberculosis cases. ${ }^{1,2}$ Molecular typing or fingerprinting investigates variations in microbial populations, defines specific clones and identifies outbreaks by matching molecular fingerprints of epidemiologically linked isolates. The combination of two or more methods, with different preselected genomic loci in the Mycobacterium tuberculosis genome, have been used to identify and track outbreaks, define high-risk groups and target prevention strategies. ${ }^{2,3,4}$ Table 1 compares three current typing methods.

In contrast to epidemiological methods, the use of genotypic methods to define clusters is controversial. Genotypedefined clusters are used to calculate the transmission index or average number of secondary cases from a single source case. These clusters appear to result from recently transmitted infection with rapid progression to clinical disease. ${ }^{5}$ Routine genotyping has shown that transmission of tuberculosis occurs more readily than previously thought, ${ }^{6}$ with substantial proportions (28-72 per cent) of urban cases occurring in clusters. ${ }^{7,8,9}$ By contrast, conventional contact tracing may identify only 10 per cent of clustered cases. ${ }^{7}$ DNA fingerprinting has demonstrated the existence and worldwide transmission of families of genetically related strains and local dissemination of successful clones.

The Centre for Infectious Diseases and Microbiology (CIDM) at Westmead has been genotyping all $M$. tuberculosis complex (including $M$. tuberculosis, $M$. africanum, M. bovis, M. bovis bacillus Calmette-Guerin (BCG), the rarely isolated species $M$. microti, $M$. canettii, and the newly described seal pathogen, $M$. pinnipedii) isolates from NSW since 2003. This report is a review of the results for the period December 2003 to May 2005.

\section{METHODS}

\section{Isolates}

All 420 M. tuberculosis complex isolates referred to the NSW Mycobacterium Reference Laboratory, CIDM, between December 2003 and May 2005, are included.

\section{Molecular typing methods}

All isolates were tested by mycobacterial interspersed repetitive units (MIRU) typing and spoligotyping, according to published methods. ${ }^{10,11}$ Clinical isolates with matching MIRU and spoligotype numerical codes were then subjected to IS6110 restriction fragment length polymorphism (RFLP) analysis. ${ }^{12}$ Quality control strains of M.tuberculosis and M.bovis BCG were used to monitor the performance of the genotyping techniques.

\section{Cluster analysis}

Comparison of IS6110 RFLP gel profiles was performed using the Bionumerics Edition 3.0 package (Applied Maths, Koutrai, Belgium) using standard methods. A cluster was

\section{TABLE 1}

COMPARISON OF CURRENT GENOTYPING METHODS USED FOR M.TUBERCULOSIS

\begin{tabular}{|c|c|c|c|c|c|c|}
\hline Name of method & $\begin{array}{l}\text { Genomic } \\
\text { target }\end{array}$ & Method & Result format & $\begin{array}{l}\text { Turnaround- } \\
\text { time }\end{array}$ & $\begin{array}{l}\text { Discriminatory } \\
\text { power }\end{array}$ & Cost \\
\hline Spoligotyping & $\begin{array}{l}\text { Direct repeat } \\
\text { region }\end{array}$ & $\begin{array}{l}\text { Single PCR; dot-blot } \\
\text { hybridisation to } \\
\text { detect presence/ } \\
\text { absence of } 43 \\
\text { spacer sequences }\end{array}$ & 15 digit code & $\begin{array}{l}\text { Days; can be } \\
\text { done directly on } \\
\text { specimens }\end{array}$ & $\begin{array}{l}\text { High sensitivity; low } \\
\text { specificity }\end{array}$ & Relatively low \\
\hline $\begin{array}{l}\text { Mycobacterial } \\
\text { interspersed repetitive } \\
\text { units (MIRU) typing }\end{array}$ & $\begin{array}{l}12 \text { loci (can be } \\
\text { more or less) }\end{array}$ & $\begin{array}{l}\text { Multiple PCR; } \\
\text { amplicons size } \\
\text { indicates number of } \\
\text { repeat sequences at } \\
\text { each locus }\end{array}$ & 12 digit code & $\begin{array}{l}\text { Days; can be } \\
\text { done directly on } \\
\text { specimens }\end{array}$ & $\begin{array}{l}\text { Depends on number } \\
\text { of loci targeted; } 12 \\
\text { loci high sensitivity; } \\
\text { moderate specificity }\end{array}$ & $\begin{array}{l}\text { Medium; } \\
\text { depends on } \\
\text { number of loci } \\
\text { targeted }\end{array}$ \\
\hline $\begin{array}{l}\text { IS6110 restriction } \\
\text { fragment length } \\
\text { polymorphism (RFLP) } \\
\text { analysis }\end{array}$ & $\begin{array}{l}\text { IS6110 } \\
\text { (0-20 copies) }\end{array}$ & $\begin{array}{l}\text { DNA cut with } \\
\text { restriction enzyme; } \\
\text { fragments } \\
\text { separated on gel; } \\
\text { probed for presence } \\
\text { of IS } 6110\end{array}$ & $\begin{array}{l}\text { Image } \\
\text { - number/size } \\
\text { of fragments } \\
\text { containing IS }\end{array}$ & $\begin{array}{l}\text { Weeks (requires } \\
\text { lots of high } \\
\text { quality DNA) }\end{array}$ & $\begin{array}{l}\text { Gold standard } \\
- \text { high specificity. Not } \\
\text { suitable for strains } \\
\text { with }<5 \text { copies of } \\
\text { IS } 6110\end{array}$ & High \\
\hline
\end{tabular}


defined as a group of isolates that were indistinguishable by all three methods. Laboratory cross-contamination, as a possible source of clustering, was investigated by checking the time of the processing in the laboratory and the clinical history of patients. The rate of recent transmission (RRT) ${ }^{13}$ was calculated as:

RRT $($ per cent $)=($ No. of isolates clustered - No. of clusters)/Total isolates typed $\mathrm{x} 100$

\section{RESULTS}

Spoligotyping identified seven of 420 (1.7 per cent) isolates as members of $M$. tuberculosis complex other than $M$. tuberculosis, namely Mycobacterium bovis (2 isolates), M.bovis BCG (3 isolates), M. canettii (1 isolate), and M.caprae (1 isolate).

\section{Molecular diversity}

Of 413 sequential isolates of M.tuberculosis, 273 (66 per cent) and 176 isolates (43 per cent) were individually grouped by spoligotyping and MIRU typing, respectively, and 105 isolates (25 per cent) were clustered by both methods. Of 273 isolates grouped by spoligotyping, 71 (26 per cent) belonged to the Beijing family of $M$. tuberculosis strains. The numbers of isolates belonging to other recognised groups are shown in Figure 1.

\section{Clusters}

Eight clusters, involving a total of 20 isolates (4.8 per cent), were identified, based on all three typing methods. Five clusters contained only two isolates, two contained three isolates and the other contained four isolates. Three stored isolates were later identified as belonging to cluster 1 .

Cluster 1 comprised six isolates: three collected during the study period and a further three isolates collected outside the study period. They were linked, but not initially recognised as being epidemiologically related, by geographic proximity and risk factors. The index case was diagnosed and treated in 2000. A sixth case was identified by routine genotyping later in the study period. The RFLP pattern for this cluster consisted of 12 bands.

\section{FIGURE 1}

\section{CLUSTERED ISOLATES BASED ON TWO PCR-BASED TYPING METHODS AND MAJOR M. TUBERCULOSIS FAMILIES IDENTIFIED BY SPOLIGOTYPING}

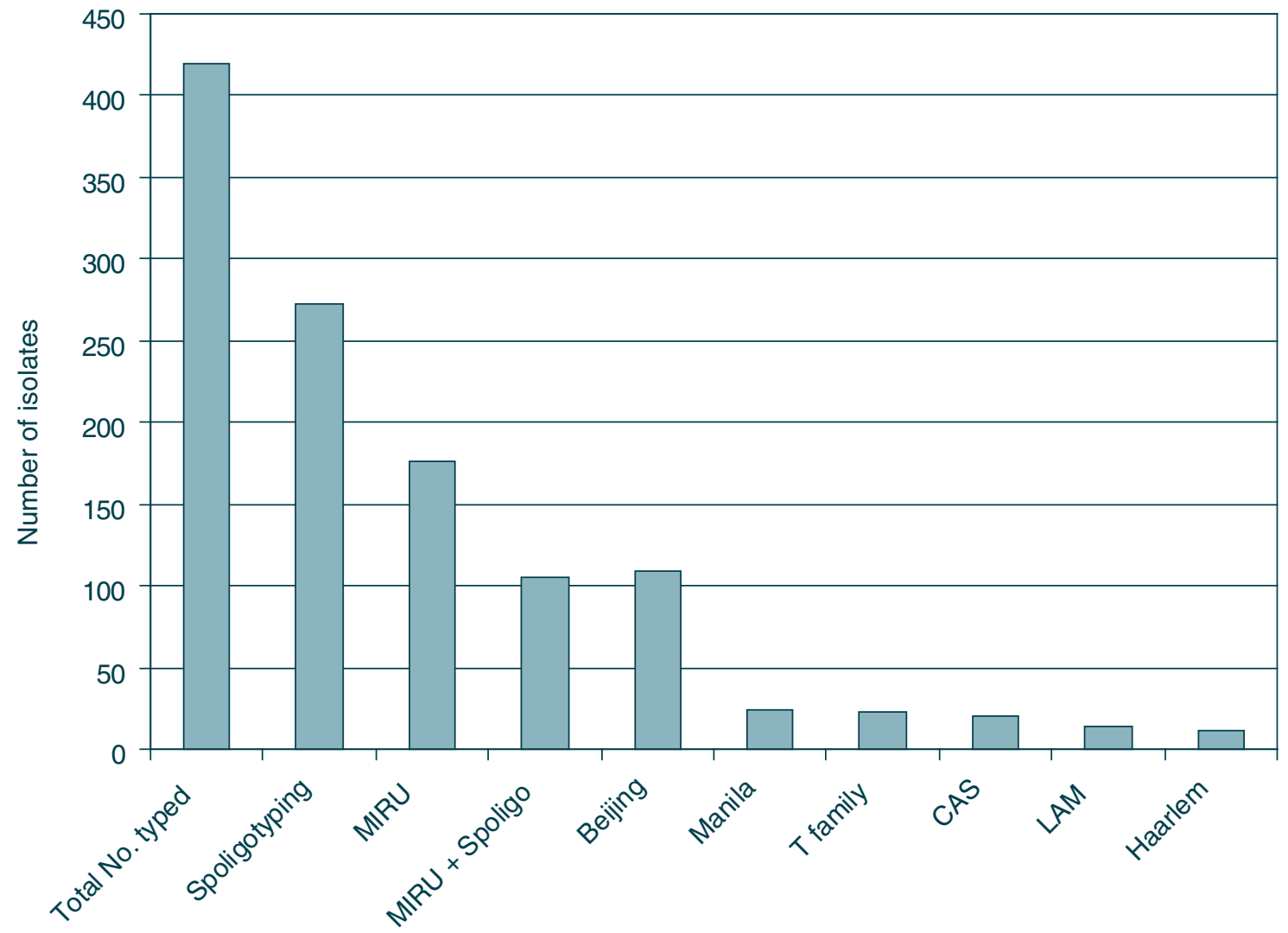

$\mathrm{PCR}=$ polymerase chain reaction

MIRU = mycobacterial interspersed repetitive units

CAS $=$ Central and Middle Eastern strain

LAM $=$ Latin American 
Clusters two, three and four consisted of isolates from patients who had recently migrated from the Philippines (four cases), the Sudan (two cases) and the Indian subcontinent (two cases), respectively. There were no identifiable links between patients within clusters; the patients' infections were probably independently acquired in their countries of origin.

Cluster five consisted of two isolates from patients who resided in different Australian states and had no obvious epidemiological links (but warrant further investigation).

Clusters six, seven and eight represented probable crosscontamination. In all three clusters there was one isolate from a patient with typical smear-positive tuberculosis; the others were from patients in whom the diagnosis of tuberculosis was considered unlikely. Clusters six and seven comprised two and three isolates respectively, referred for confirmatory identification. Isolates in both clusters were recovered from specimens from different patients, processed in the same laboratories at the same time. The two isolates in cluster eight were recovered from patients who had attended the same clinic for bronchoscopy two weeks apart; the same bronchoscope was used for both procedures.

Only patients from clusters one and five were included in the calculation of the rate of recent transmission (RRT), which was calculated as 1.4 per cent (Table 2).

\section{DISCUSSION}

Our results highlight the diversity of M. tuberculosis strains involved in tuberculosis infections in this country, most of these infections being acquired elsewhere. The most prominent strains identified during the study by spoligotyping belong to the W-Beijing family (more than one quarter of all isolates examined), which was first described in China and neighbouring countries in $1995^{14}$ and has since spread to many parts of the world, especially Asia and Russia., ${ }^{2,15,16}$ They are highly transmissible and often found predominantly in younger patients and they have an increased tendency to develop multidrugresistance. ${ }^{15,16}$ There is some evidence that $B C G$ vaccination is less effective against Beijing genotype strains than others. ${ }^{17}$ The high proportion of Beijing genotype strains reflects the migration patterns into NSW.

The low level of clustering of M.tuberculosis isolates in this study confirms that recent transmission of tuberculosis in NSW is uncommon. Several clusters may reflect reactivation of latent tuberculosis infections in migrants from high incidence countries where $M$. tuberculosis strains are more homogenous. ${ }^{3,18}$ However, the possibility of recent transmission from direct contact, for example in a refugee camp or detention centre before arrival in Australia, cannot always be excluded. The rate of recent transmission (1.4 per cent) in this study is lower than that reported from other low-incidence countries (Table 2). However, these findings should be interpreted with caution. Studies of short duration (i.e. less than two years) may significantly underestimate the level of clustering because of the long incubation period of tuberculosis. ${ }^{2,20,21}$ Cluster 1, in this study, was identified because of genotyping of more recent isolates several years after the first three cases had presented. Cluster size can be significantly underestimated unless a high proportion of the total isolates from a population over a significant period (usually at least 3 years) are genotyped. ${ }^{22}$

There is a growing body of evidence to support the role of M. tuberculosis genotyping in the detection and tracking of outbreaks of infection., ${ }^{4,618}$ Increased migration from high-prevalence areas increases the risk of spread of multidrug-resistant $M$. tuberculosis and the need for earlier detection of outbreaks. ${ }^{23}$ Clustering reflects the efficiency of therapy, the interval between disease onset and the start of treatment and the regional dominance of more successful strains of M. tuberculosis. ${ }^{22} \mathrm{~A}$ better knowledge of expanding clones, such as the Beijing strain, is urgently needed in order to define better control measures. ${ }^{4,23,24}$

\section{TABLE 2}

COMPARISON OF FINDINGS FROM NSW WITH THREE RECENT INTERNATIONAL STUDIES THAT HAVE USED MOLECULAR TYPING OF M.TUBERCULOSIS TO DESCRIBE THE EPIDEMIOLOGY OF THE DISEASE

\begin{tabular}{|c|c|c|c|c|}
\hline & London, UK ${ }^{13}$ & Denmark $^{18}$ & Italy ${ }^{19}$ & NSW (this study) \\
\hline Number of isolates genotyped & 57 & 1549 & 248 & 420 \\
\hline Methods used & $\begin{array}{l}\text { IS6110 RFLP, } \\
\text { spoligotyping }\end{array}$ & IS6110 RFLP & $\begin{array}{l}\text { IS6110 RFLP, } \\
\text { spoligotyping }\end{array}$ & $\begin{array}{l}\text { IS6110 RFLP, } \\
\text { spoligotyping, MIRUs }\end{array}$ \\
\hline Duration of study & 3 years & 5 years & 1 year & 1.5 years \\
\hline Rate of clustering \% & 15.8 & 49 & 33 & 4.9 \\
\hline Recent transmission rate \% & 8.8 & $57^{*}$ & 15 & 1.4 \\
\hline $\begin{array}{l}\text { Percentage of tuberculosis due to } \\
\text { Beijing strain }\end{array}$ & Not reported & Not reported & 2.8 & 25.9 \\
\hline
\end{tabular}

RFLP = restriction fragment length polymorphism; MIRU = mycobacterial interspersed repetitive units.

*Active transmission among native Danes reported only (two strains were responsible for $40 \%$ of all clustered cases among native Danes; the sample included two large clusters among HIV positive drug users). 
No single typing method is ideal. PCR-based methods are rapid and relatively inexpensive; when combined, they can quickly exclude clustering in three quarters of cases, significantly reducing the need for IS6110 RFLP typing. Patients who need additional follow-up can be identified more rapidly, secondary cases treated more quickly and new cases prevented. Although IS6110 is regarded as the 'gold standard' it often requires several weeks' culture of $M$. tuberculosis to obtain adequate DNA and inter-laboratory comparison of results can be difficult. Spoligotyping alone is relatively non-discriminatory but provides valuable data about the prevalence of various $M$. tuberculosis families and can rapidly differentiate sub-species within the $M$. tuberculosis complex (for example M.bovis, M.bovis BCG, and M.canetii), which can otherwise only be identified by time-consuming biochemical tests. As far as we know, this is the first time that $M$. canetti and $M$. caprae have been identified in Australia. ${ }^{25}$ The combination of three methods, as used in NSW, is probably the most cost-effective approach in the long term if clustered cases are rapidly identified and investigated, but more detailed analysis of data, over a longer period, is required.

These data will be used in future as a baseline for real-time monitoring of transmission dynamics of tuberculosis cases in NSW. They will contribute to a national genotyping project (based on MIRU typing only, initially), which may identify links between patients travelling interstate (such as those in cluster five). A project is currently in progress in NSW to link the genotyping database with tuberculosis case notification data. A comprehensive national tuberculosis genotyping network linked to the National Notifiable Diseases Surveillance System would provide continuous monitoring of transmission trends and allow identification of widespread outbreaks.

\section{ACKNOWLEDGEMENTS}

Genotyping of M.tuberculosis isolates was funded by the NSW Department of Health. We also gratefully acknowledge the help of Ms Julie Hunt in collecting epidemiological information.

\section{REFERENCES}

1. Dye C, Williams BG, Espinal MA, Raviglione MC. Erasing the world's slow stain: strategies to beat multidrug-resistant tuberculosis. Science 2002; 295: 2042-6.

2. Nguyen LN, Gilbert GL, Marks GB. Molecular epidemiology of tuberculosis and recent developments in understanding the epidemiology of tuberculosis. Respir 2004; 9: 313-9.

3. Seilder A, Nienhaus A, Diel R. The transmission of tuberculosis in the light of new molecular biological approaches. Occup Environ Med 2004; 61: 96-102.

4. Malik ANJ, Godfrey-Faussett P. Effects of genetic variability of Mycobacterium tuberculosis strains on the presentation of disease. Lancet Infect Dis 2005; 5: 174-83.

5. Van Deutekom H, Hoijng SP, de Haas PEW, Langendam MW, et al. Clustered tuberculosis cases: Do they represent recent transmission and can they be detected earlier? Am J Respir Crit Care Med 2004; 169: 806-10.

6. Heldal E, Docker H, Caugant DA, Tverdal A. Pulmonary tuberculosis in Norwegian patients. The role of reactivation, re-infection and primary infection assessed by previous mass screening data and restriction fragment length polymorphism analysis. Int J Tuberc Lung Dis 2000; 4: 300-7.

7. Small PM, Hopewell PHC, Singh SP, Paz A, et al. The epidemiology of tuberculosis in San Francisco: A populationbased study using conventional and molecular methods. $N$ Engl J Med 1994; 330: 1703-9.

8. Jasmer RM, Hahn JA, Small PM, Daley CL, et al. A molecular epidemiologic analysis of tuberculosis trends in San Francisco, 1991-1997. Ann Intern Med 1999; 130: 971-8.

9. Geng E, Kreiswirth B, Driver C, Li J, et al. Changes in the transmission of tuberculosis in New York City from 1990 to 1999. N Eng J Med 2002; 346: 1453-8.

10. Kamerbeek J, Schouls L, Kolk A, van Agterveld M, et al. Simultaneous detection and strain differentiation of Mycobacterium tuberculosis for diagnosis and epidemiology. J Clin Microbiol 1997; 35: 907-14.

11. Supply P, Lesjean S, Savine E, Kremer K, van Soolingen D, Locht C. Automated high-throughput genotyping for study of global epidemiology of Mycobacterium tuberculosis based on mycobacterial interspersed repetitive units. J Clin Microbiol 2001; 39: 3563-71.

12. Van Embden JD, Cave MD, Crawford JT, et al. Strain identification of Mycobacterium tuberculosis by DNA fingerprinting: Recommendations for a standardized methodology. J Clin Microbiol 1993; 31: 406-9.

13. Shemko M, Yates M, Fang Z, Gibson A, Shetty N. Molecular epidemiology of Mycobacterium tuberculosis in patients of Somalian and white ethnic origin attending an inner London clinic. Int J Tuberc Lung Dis 2004;8:186-93.

14. Van Soolingen D, Qian L, de Haas PE, et al. Predominance of a single genotype of Mycobacterium tuberculosis in countries of East Asia. J Clin Microbiol 1995; 33: 3234-8.

15. Glynn JR, Whiteley J, Bifany PJ, Kremer K, van Soolingen D. Worldwide occurrence of Beijing/W strains of Mycobacterium tuberculosis: A systematic review. Emerg Infect Dis 2002; 8: 843-9.

16. Kubica T, Rusch-Gerdes S, Niemann S. The Beijing genotype is emerging among multidrug-resistant Mycobacterium tuberculosis strains from Germany. Int J Tuberc Lung Dis 2004; 8: 1107-13.

17. Anh DD, Van Borgdorff MW, Van LN, et al. Mycobacterium tuberculosis Beijing genotype emerging in Vietnam. Emerg Infec Dis 2000; 6: 302-5.

18. Bauer J, Yang Z, Poulsten S, Andersen AB. Results from 5 years of nationwide DNA fingerprinting of Mycobacterium tuberculosis complex isolates in a country with a low incidence of M.tuberculosis infection. J Clin Microbiol 1998; 36: $305-8$.

19. Lari N, Rindi L, Sola C, Bonanni D, et al. Genetic diversity, determined on the basis of katG463 and gyrA95 polymorphism, spoligotyping, and IS6110 typing, of Mycobacterium tuberculosis complex isolates from Italy. $J$ Clin Microbiol 2005; 43: 1617-24.

20. Van Soolingen D. Molecular epidemiology of tuberculosis and other mycobacterial infections: main methodologies and achievements. J Intern Med 2001; 249: 1-26. 
21. Glynn JR, Vynnycky E, Fine PE. Influence of sampling on estimates of clustering and recent transmission of Mycobacterium tuberculosis derived from DNA fingerprinting techniques. Am J Epidemiol 1999; 149: 366-71.

22. Glynn JR, Yates MD, Crampin AC, Ngwira BM, et al. DNA fingerprint changes in tuberculosis: Reinfection, evolution, or laboratory error. J Infect Dis 2004; 190: 1158-66.

23. Bayona J, Chavez-Pachas AM, Palacios E, Llaro K, et al. Contact Investigations as a means of detection and timely treatment of persons with infectious multidrug-resistant tuberculosis. Int J Tuberc Lung Dis 2003(Suppl): S501-9.
24. Borgdorff MW, Nagelkerke N, van Soolingen D, de Haas PE, et al. Analysis of tuberculosis transmission between nationalities in the Netherlands in the period 1993-1995 using DNA fingerprinting. Am J Epidemiol 1998; 147: 187-95.

25. Sintchenko V, Jelfs P, Dally M, Crighton T, Gilbert GL. A case of urinary tuberculosis due to Mycobacterium bovis subsp. caprae. Pathology 2006 (in press). 